\title{
Los clowns de Maria Zambrano y la Generación del 27
}

\author{
Clowns in María Zambrano \\ and the Generation of the 27th \\ Carlos Gutiérrez Bracho \\ Centro de Estudios, Creación y Documentación de las Artes (CECDA), \\ Universidad Veracruzana, México \\ cagubra@gmail.com
}

DOI: https://doi.org/10.15366/bp2020.25.010

Bajo Palabra. II Época. No25. Pgs: 221-238 


\section{Resumen}

En "El payaso y la filosofía", María Zambrano reflexiona sobre la actuación de uno de los artistas clown más importantes del siglo XX, en Europa: Grock. En este texto, encuentra una similitud entre el filósofo y el payaso. Aunque se trata de un tema poco recurrente en la obra de esta pensadora, la vincula a los intelectuales de la Generación del 27, que dio lugar a "una nueva edad de oro" en la literatura española, porque algunos de sus miembros mostraron alto interés por los clowns, entre ellos Federico García Lorca, León Felipe y Rafael Alberti, así como algunos de los que pertenecieron a la llamada "otra" generación del 27, como Ramón Gómez de la Serna. Así, este trabajo trata sobre cómo, en un tiempo anterior a la Guerra Civil española, estos intelectuales encontraron, en la figura cómica, oportunidad para hablar de la lucha por la libertad y de una nueva dimensión de la experiencia humana.

\section{Abstract}

In "El Payaso y la Filosofía", Maria Zambrano reflects on the performance of one of the most important clown artists in the twentieth century in Europe: Grock. In this text, she finds a similarity between the philosopher and the clown. While it is a little recurring issue in the works of the woman philosopher, it links her with the rest of the scholars of the Generation of the $27 \mathrm{th}$, that meant "a new golden age" in the Spanish literature, because some of the members of this generation showed a deep interest in clowns. Among them, Federico García Lorca, Leon Felipe and Rafael Alberti, as well as some of the ones in the so called other "Generation of the 27th", as Ramón Gómez de la Serna. Thus, this paper seeks how, in a time before the Civil War in Spain, these intellectuals found an opportunity, in the figure of the comedian, to talk about the fight for freedom and, there, a new dimension in human experience.

Keywords: clown, Charlotism, clownism, smile, philosophy, Gomez de la Serna, Garcia Lorca, Rafael Alberti. 
L a nota tenía un título sencillo: "El clown Grock". Apareció el 13 de octubre de 1932 en el periódico Luz. Diario de la República y daba cuenta de una serie de presentaciones, en el Circo Price de Madrid, de "el clown más importante del mundo” en aquellos años. Ese texto escrito por Ramón Gómez de la Serna recordaba que un día Grock hizo llorar a los negros, en una playa de Cabo Verde, donde "dió [sic] una representación dedicada a los indígenas y tuvo que suspender sus carantoñas porque las lágrimas comenzaron a correr por las mejillas de los negros convulsos" ${ }^{1}$. ¿Qué pasó en esa ocasión?, se preguntaba el escritor y daba una respuesta: "[q] ue aquellos seres primitivos y de color habían visto la negativa de la placa, las negruras subvertidas al blanco y a los amarillos subvertidos al negro", porque ellos, "los salvajes", habían visto "a la muerte y a la desesperación en las cabriolas y tozudeces de Grock" 2 .

Hoy, algunos se preguntarán quién era Grock. Fue un clown de origen suizo - su nombre real, Charles Adrien Wettach-. Era hijo de un relojero y comenzó su carrera escénica en el cabaret. En 1903 se asoció con un clown llamado Brick, y juntos dieron funciones en Francia, África y América; años después, Grock actuó con Umberto Guillaume, otro clown que tuvo como nombre artístico Antonet, y se hicieron muy famosos en Europa. Una de las que acudieron al llamado para ver una de sus funciones en el Circo Price fue María Zambrano. Dos décadas después de esa temporada, en su tránsito por La Habana, en Cuba, ella escribió "El payaso y la filosofía", un pequeńo ensayo sobre la experiencia que le provocó la presentación de este clown en Madrid. "Recuerdo al viejo Grock sonreír a una multitud inmensa de todas las edades y clases sociales en el Circo de Price, de un Madrid ya angustiado en ese período más angustioso aún que la postguerra, que es la preguerra (Del que no sé por qué no suele hablarse nunca)" ${ }^{3}$. Para Zambrano, la de Grock y de los payasos en general es una forma de arte humilde, popular, que se destaca por ser "de todos", por ser una de las obras máximas del humano ingenio y que son, "al par, el pan de cada día", porque "una obra de arte alcanza su fin cuando se convierte en alimento para todos" 4 .

\footnotetext{
$\overline{1}$ Gómez de la Serna, R., "El clown Grock", en Luz, 13 octubre de 1932, p. 9.

2 Ibid.

3 Zambrano, M., "El payaso y la filosofía, en Aurora (2012), p. 117.

4 Ibid.
} 
En su escrito, María Zambrano reflexiona sobre la actuación de Grock. Encuentra, a partir de esa experiencia vivida en los ańos 20, una similitud entre el filósofo y el payaso. El primero, dice, es el que piensa, mientras que el payaso "mimetiza desde siempre y con éxito infalible el acto de pensar, con todo lo que el pensamiento comporta: la vacilación, la duda, la aparente indecisión. El aleja-

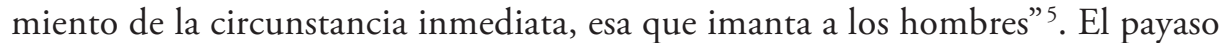
mimetiza, dice Zambrano, "esa peculiar situación" de quien se puede mover "en otro espacio libre y vacío" ${ }^{\text {. }}$

"El payaso y la filosofía" es un texto breve, es cierto, pero no por ello irrelevante. En él, la filósofa no sólo habla de la figura cómica, sino de ella misma; así, reflexiona sobre lo que le significa "pensar", como una experiencia activa; lo que ha sido ser poeta y ser filósofa; además, de manera indirecta, habla de lo que ha significado la libertad para la generación a la que se le ha vinculado: la del 27, a pesar de que Zambrano consideró que nunca perteneció a ningún grupo ${ }^{7}$. Sin embargo, el payaso no sólo despertó inquietudes en esta pensadora. Es, precisamente, la atención que ella le dedica a esta figura uno de los aspectos que la vinculan a los intelectuales del 27, porque, en este grupo, algunos de sus miembros mostraron alto interés por los clowns, seres aparentemente insignificantes, pero que les abrieron la posibilidad de encontrarse en la mirada del otro, de mirarse a sí mismos y de descubrir una nueva dimensión de la experiencia humana.

\section{Generación del 27}

Los INTELECTUALes QUE CONFORMAN la llamada Generación del 27 nacieron entre 1898 y 1914; la gran mayoría residió, estudió y desarrolló su trabajo intelectual y artístico en Madrid. Muchos de ellos comenzaron a mostrar su obra en la década de los ańos 20 y se encontraban receptivos a la modernidad, a las vanguardias, pero también a la tradición popular española. Además, fueron "sensibles a una realidad social con la que se sentían comprometidos, fueron capaces de transformar el panorama cultural y artístico de una España en proceso de cambio" ${ }^{8}$. Federico García Lorca, Luis Cernuda, Pedro Salinas, Rafael Alberti, León Felipe, Vicente Aleixandre, Dámaso Alonso y Juan José Domenchina, son algunos de los nombres

\footnotetext{
5 Ibid., p. 118.

6 Ibid.

7 Berenguer Vigo, A., María Zambrano y la raiz desnuda, Libros.com, 2016 (versión electrónica).

${ }^{8}$ Balló, T., Las sinsombrero. Sin ellas, la historia no está completa. Madrid, Planeta, 2016 (versión electrónica).
} 
vinculados a este grupo. A las mujeres de esta generación se les conoce como "las Sinsombrero", concepto acuñado durante un paseo que hicieron Federico García Lorca, Salvador Dalí, Maruja Mallo y Margarita Manso, por el Madrid de los 20․, porque "las figuras femeninas emergen como personajes pictóricos o literarios fuertes, emancipados, que luchan contra su destino" ${ }^{10}$. Entre ellas están, por citar algunas, Rosa Chacel, Concha Méndez-Cuesta y María Teresa León.

Se considera que la Generación del 27 forjó "una nueva edad de oro" en la literatura española, integrada a la estética del modernismo europeo, y que buscaba preservar la experiencia humana a través de la metáfora, el cine y la reivindicación de lo pequeño, entre otros elementos ${ }^{11}$. Se trata de un grupo "compacto y novedoso" dentro de la literatura española, que fue "silenciado" durante la dictadura que siguió a la Guerra Civil ${ }^{12}$. Se le contextualiza en los años anteriores a la Guerra Civil española, que fue el tiempo en que sus integrantes mostraron su "talento creativo con más fuerza" ${ }^{13}$; después, muchos de ellos vivieron el exilio, con sentimientos de desarraigo por tener que vivir alejados de su tierra natal y sentir, en algunos casos - como ocurrió con Zambrano-, que ahí se encontraba la verdadera experiencia de lo humano: el no pertenecer, el sentir la propia vida como un viaje en intemperie existencial.

Basado en los apuntes de Pedro Laín Entralgo, Santiago Fortuño Llorena habla de una "otra" generación del 27, identificada por ser renovadora del humor contemporáneo y que surgió a la par de la generación de los poetas y escritores citados anteriormente. Entre ellos, distingue a Ramón Gómez de la Serna, Julio Camba, Wenceslao Fernández Flórez, Antonio de Lara Tono, Edgar Neville, Enrique Jardiel Poncela, Miguel Mihura y José López Rubio. Ellos le dan alto valor al humor discreto, el que busca una sonrisa más que una carcajada, "un humor que requiere una pequeña preparación mental para su comprensión, que incide antes en el cerebro que en los nervios" ${ }^{14}$. Ellos retomaron,

[...] tal vez sin tener plena conciencia de ello, la afirmación que hizo José Ortega y Gasset en 1906, de que el arte aísla de la vulgaridad, de modo que el humorismo deviene, en

\footnotetext{
${ }^{9}$ Díaz Pardo, F., Breve historia de la Generación del 27. Vanguardias españolas, Madrid, Nowtilus, 2018 (versión electrónica).

${ }^{10}$ Balló, T., Las sinsombrero. Sin ellas, la historia no está completa, o. c.

${ }^{11}$ Huárag Álvarez, E., Generación del 27. Virtuosismo metafórico y hondura existencial, Lima, Pontificia Universidad Católica del Perú, 2004, pp. 11-12.

${ }_{12}$ Díaz Pardo, F., Breve historia de la Generación del 27. Vanguardias españolas. o. c.

13 Ibid.

${ }^{14}$ Fortuño Llorens, S., Vanguardia y humorismo. La otra generación del 27, Valencia, Universitat Jaume I, 1998, p. 7.
} 
opinión de Wenceslao Fernández Flórez, en una posición ante la vida, en la sonrisa de una desilusión, que supone un desfase entre lo real y lo ideal ${ }^{15}$.

No obstante, los miembros de esta "otra" generación fueron calificados como representantes del llamado "teatro de evasión", "cultivadores de la 'alta comedia", de la "comedia burguesa" o del "teatro de derechas" 16 .

El ensayo "El payaso y la filosofía" evidencia cómo María Zambrano compartía con los intelectuales de su época reflexiones similares en torno a la sonrisa, al humor y a la figura del payaso. Este interés se dio, de acuerdo con José Luis Plaza Chillón, por influencia por las vanguardias europeas del siglo xx y porque la imagen del clown no era sólo un motivo pictórico o literario, sino que les hacía plantearse la cuestión del arte ${ }^{17}$. En este sentido, este investigador resalta las aportaciones de Jacinto Benavente, Ramón María del Valle-Inclán y del propio Gómez de la Serna. Este último se convirtió, asimismo, en un referente obligado del tema a principios del siglo xx en Espańa, porque fue reconocido como un cronista de circo, para quien "toda la magia está en el clown" ${ }^{18}$. De ahí que no fuera casualidad que la nota del periódico Luz sobre la presencia del clown Grock en Madrid hubiera sido encomendada a Gómez de la Serna, quien tenía una visión existencialista de esta figura. Decía, por ejemplo, que el clown "es el que sostiene el circo y quizá sostiene la vida, siendo lo que más consuelo nos da, después de nuestra muerte, ellos continuarán sus payasadas" ${ }^{19}$. Gómez de la Serna también observó el trabajo cinematográfico de Charles Chaplin y a partir de éste propuso el término "charlotismo", para describir una de las vanguardias importantes de aquellos años. Para él, con su personaje, Chaplin rompió la "gravedad de asno que caracterizaba al mundo y que todavía lo caracteriza en buena parte. Es algo así como la danza de un hombre solo en medio de las vanidades del mundo y de las fiestas encopetadas" 20 .

Gómez De la Serna mira en Charlot a ese bailarín solitario que, como polichinela modern-style, "se siluetea en la noche de nuestro tiempo" ${ }^{21}$; también, "la seriedad que hace burla seria a espaldas de la risa, cuando generalmente lo que suele pasar

\footnotetext{
15 Ibid., p. 8 .

16 Ibid.

17 Plaza Chillón, J.L., "Payasos, pierrots y saltimbanquis: su dimensión autobiográfica y social en Picasso y Federico García Lorca”, en Cuadernos de Arte Granada, 43 (2012), p. 96.

18 Ibid.

19 Ibid.

20 Ortega, J., Chaplin. La sonrisa del vagabundo. Berenice, 2008 (versión electrónica).

${ }^{21}$ Gómez de la Serna, R., Ismos, Madrid, Guadarrama, 1975, p. 256.
} 
es que la risa hace ademanes a la espalda de la seriedad" 22 ; considera que cualquier opinión sobre este personaje no puede hacerse con la lógica de "un estudio cualquiera" ${ }^{23}$, porque él es el "gran distraído, distraído sumo, el distraído en libertad, el distraído feroz" ${ }^{24}$. Es Charlot, en la interpretación de Gómez de la Serna, la figura del pequeño, del invisible en la sociedades, del que ya nadie ve, porque no se alcanza a saber quién está más distraído en este mundo de vanidades. Charlot se vuelve tan insignificante para quien no quiera verlo que hasta Gómez de la Serna pone en duda su existencia. Algunos miembros de la Generación del 27 sí estuvieron atentos para notarlo, no sólo a él, sino a las miles de figuras anónimas clown que le dieron sentido.

\section{Origen del clownismo español}

EN LA COMUNIDAD ARTística e intelectual madrileña de los años 20, una charla causó un interés particular: el pintor uruguayo Rafael Pérez Barradas participó de una velada "ultraísta" en El Ateneo, donde ofreció una conferencia titulada "El anti-yo, estudio teórico sobre el clownismo y dibujos en la pizarra". Aunque la conferencia no nos ha llegado de manera directa al presente, se conocen algunos detalles que fueron publicados, en mayo de 1921, en el número 10 del journal Ultra, titulado "Kaleidoscopio. Nuestra segunda velada". En dicho texto se consigna que la velada tuvo lugar el sábado 30 de abril de 1921 y ahí

[s]e leyeron cuartillas sobre estética ultraísta, se pronunciaron palabras bautismales y se recitaron poemas [...] a pesar de las protestas de una exigua minoría retardataria y obtusa, que originó la indignación del público en general al grito de "idiotas los que protestan", lanzado valientemente por Andrés González-Blanco, fogoso defensor del arte nuevo ${ }^{25}$.

Fue, pues, a través de charlas de café, como Barradas logró seducir a los artistas e intelectuales sobre la profunda dimensión del clown plasmada en sus obras ${ }^{26}$, las cuales pueden ser vistas como antecedente de los arlequines, pierrots y clowns que Federico García Lorca pintó tiempo después. En una publicación especial sobre Barradas, en mayo de 2013, el diario El Pais definía al clownismo como

\footnotetext{
22 Ibid., p. 258.

23 Ibid., p. 261.

${ }^{24}$ Ibid., p. 262.

25 Peral Vega, E. Pierrot/Lorca. White Carnival of Black Desire, Tamesis: Boydell \& Brewer, 2015, p. 62.

${ }^{26}$ Plaza Chillón, J.L., "Payasos, pierrots y saltimbanquis: su dimensión autobiográfica y social en Picasso y Federico García Lorca”, op. cit., p. 100.
} 
[...] la nueva onda que practicó Barradas, recién salido del vibracionismo, aunque en algunos casos [ejercía] las vanguardias al mismo tiempo. Si se lo mira con atención, el clownismo se adaptaba con facilidad al estilo caricaturesco que el pintor nunca dejará de lado ${ }^{27}$.

Además, en el especial se preguntaba “¿Por qué clownismo?”. Y hacía una analogía entre los rostros de las figuras clown y los retratos de los poetas Gabriel García Maroto y García Lorca, quienes "gastaron el maquillaje enharinado de los payasos y la alteración de sus rasgos físicos. García Lorca es García Lorca gracias a los reconocible de sus cejas. A Maroto le llevó más tiempo que lo identificaran” ${ }^{28}$. De acuerdo con este texto, ambos artistas fueron dibujados como clowns por Barradas, con lo que ejemplifican la llamada "segunda vanguardia" creada por el pintor uruguayo.

La influencia de Barradas es visible tanto en escritores como pintores. Uno de ellos es Alberto Sánchez Pérez, quien llegó a tener, a partir de 1922, una entrańable amistad con el artista latinoamericano, por quien conoció "la eclosión de las vanguardias en Milán, París, Barcelona y Madrid" y se dejó influenciar por las preocupaciones artísticas del uruguayo, por lo que que "trufaría de vocación social la andadura 'vibracionista' y 'clownista' que hasta ahora había conducido su pintura" ${ }^{29}$. En Pierrot/Lorca, Emilio Peral Vega considera que no es coincidencia que Barradas fuera llamado "el padre del clownismo". En su libro Ismos (1931), Ramón Gómez de la Serna no considera este término dentro de sus descripción de vanguardias, aunque entre los 25 términos que incluyó sí se encuentra "humorismo", el cual, explica, "inunda la vida contemporánea, domina casi todos los estilos y subvierte y exige posturas en la novela contemporánea" ${ }^{30}$. Profundiza:

La actitud más cierta ante la efimeridad de la vida es el humor. Es el deber racional más indispensable, y en su almohada de trivialidades, mezcladas de gravedades, se descansa con plenitud.

Se sobrepasa, gracias al humor, esa actitud por la que sólo se es un profesional del vivir, en toda la sumisión que representa ese profesionalismo.

El humor ha acabado con el miedo, debe acabar aún más con él. Cosa importantísima, porque sabido es que el miedo es el peor consejero de la vida, el mayor creador de obsesiones y prejuicios.

\footnotetext{
${ }_{27}$ El País, "Rafael Barradas", en El País, Madrid (2013), (versión electrónica).

${ }^{28} \mathrm{Ibid}$.

${ }_{29}$ Brihuega, J., 2015, "El fulgor de un epílogo. Dos obras de la última etapa de Alberto". Museo de Bellas Artes de Bilbao, p. 6. (versión electrónica).

${ }^{30}$ Gómez de la Serna, R., Ismos, op. cit., p. 197.
} 
El humorismo es una anticipación, es echarlo todo en el mortero del mundo, es devolvérselo todo al cosmos un poco disociado, macerado por la paradoja, confuso, patas arriba ${ }^{31}$.

En Ismos, Gómez de la Serna escribe que el humor, más que género literario, es un género de vida $\mathrm{o}$, incluso, una actitud frente a la vida ${ }^{32}$; es, asimismo, una forma de comportamiento, "una obligación de alta mar en los siglos, es una condición de superioridad" ${ }^{33}$, porque el humor "entra en las cosas por el lado por el que no existen, y que es el que las revela más" ${ }^{4}$. Además, defiende que la mujer no sea clown, "porque su coquetería se opone a ello" ${ }^{35}$ y porque la han enseñado a llorar y el humor es una fórmula para evaporar esas lágrimas ${ }^{36}$; asimismo, está convencido de que a ella la han educado para "agradar con sus gracias, mantenidas en un solo sentido de armonía" ${ }^{37}$. Diferencia, sin embargo, a los clowns de los humoristas: "el humorista es un ser enlutado por dentro que hace sufrir la alegría. Ama los clowns y no tiene que ver nada con ellos, pues también ama los enterradores y no tiene tampoco que ver nada con esos lúgubres oficiantes" ${ }^{38}$.

El clownismo, definido por Eugenio Carmona:

[...] apela al mundo del circo y de la guardarropía. Pero existen pocas pinturas al óleo identificadas como clownistas. La mayoría de las composiciones afirmadas como tales son dibujos y acuarelas. En estos dibujos y acuarelas las figuras, quietas y en pose, están siempre en primer plano, resueltas con trazos ágiles y nerviosos, con aspectos de abocetado. Pero lo que sin duda define el clownismo son los rostros. Unos rostros planos y de óvalo bien delimitado que tienen el espacio ocular apenas insinuado, pero que, sin embargo, nos miran con una profundidad inquietante. ${ }^{39}$

De esta descripción llama la atención un aspecto fundamental en el arte del clown: la mirada. Y la mirada, en el pensamiento de María Zambrano, aunque efímera, es vista como la huella de la relación con el otro, como uno de los elementos esperanzadores en el tránsito por el exilio.

\footnotetext{
31 Ibid., p. 199.

32 Ibid., p. 200.

33 Ibid., p. 203.

${ }^{34}$ Ibid., p. 205.

35 Ibid., p. 206.

36 Ibid.

37 Ibid., p. 207.

38 Ibid., p. 211.

39 Una descripción exactamente igual se encuentra en el ensayo "Payasos, pierrots y saltimbanquis: su dimensión autobiográfica y social en Picasso y Federico García Lorca”, de José Luis Plaza Chillón (2012).
} 


\section{Los otros clowns}

En NOviembre De 1929, Rafael Alberti causó un enorme escándalo en el Lyceum Club, porque presentó una conferencia titulada "Palomita y galápago: No más artríticos", en la que apareció vestido de payaso, acompañado por una paloma, una tortuga y galápago. Durante su intervención lanzaba "duras críticas" contra Valle-Inclán, Juan Ramón Jiménez, Antonio Machado, Ortega y Gasset, así como Eugenio D’Ors. Una de las asistentes al acto, Ernestina de Champourcin, describió su indumentaria como "una perfecta imitación cinematográfica que casi nadie entendió" ${ }^{40}$. Según las descripciones, en esta conferencia Alberti estaba vestido con pantalones con forma de fuelle y un cuello almidonado propio del traje de un payaso, con el que imitaba a dos grandes cómicos del cine de aquella época: Charles Chaplin y Buster Keaton. "[E] nmascarado en el puro vanguardismo revolucionario, parece ser que la intención de Alberti era más bien desconcertar a las socias del Lyceum" ${ }^{41}$.

Lo que Alberti veía en Keaton o en Chaplin era "su inadaptación al mundo moderno, que genera en ellos un sempiterno sentimiento de fracaso, de pérdida: la pérdida de un universo idealizado donde todo era más humano, más auténtico; un universo que, tal vez, nunca existiera realmente, más allá de en sus mentes idealistas" ${ }^{42}$. Los escogió por lo que simbolizaban a los reveladores del futuro, "a quienes traducían en la pirueta una realidad desesperada" ${ }^{43}$. Además, Alberti tenía la capacidad de encontrar la tristeza que se oculta detrás del humor de estos personajes, "pues al recrear las bufonadas de los tontos del cine mudo capta[ba] también y de manera más significativa la melancolía que yace debajo de gran parte de sus tonterías" ${ }^{44}$.

En 1929, Alberti escribió el poema "Yo era un tonto y lo que he visto me ha hecho dos tontos", inspirado en dos versos de La hija del aire de Calderón de la Barca. En Alberti, explica Jaime Siles, "[l] os tontos son encarnación de la figura del poeta en el mundo real” ${ }^{45}$. Por su parte, Marina Casado considera que Alberti se identificó públicamente con los tontos y tenía la intención de "provocar al mundo,

${ }_{40}$ Citado en Ripoll, J.R., "Primera lectura de Marinero en tierra", en: Martínez Torrón, D. Juan Ramón, Alberti. Dos poetas líricos, Kassel, Reichenberger, 2006, p. 220.

${ }^{41}$ Citado en Navas Ocaña, I., "Las escritoras del 27 y los cometas", en Romance Notes, University of North Carolina at Chaple Hill, Vol. 50, No. 2 (2010), pp. 244.

42 Casado, M., La nostalgia inseparable de Rafael Alberti. Oscuridad y exilio intimo en su obra, Madrid, De la Torre, 2017, pp. 102-103.

${ }^{43}$ Gullón, R., 1984, p 241, citado en Casado, M., La nostalgia inseparable de Rafael Alberti. Oscuridad y exilio intimo en su obra, op. cit., p. 102.

${ }_{44}$ Geist, 2003, p. 125, citado en Casado, M., La nostalgia inseparable de Rafael Alberti. Oscuridad y exilio intimo en su obra, op. cit., p. 102.

45 Casado, M., La nostalgia inseparable de Rafael Alberti. Oscuridad y exilio intimo en su obra, op. cit., p. 109. 
de rebelarse, como si tratara de dejar claro que todos aquellos actores de cine mudo lo representaban, en su sentimentalidad patética e idealista" ${ }^{46}$.

Otro de los textos de Alberti, alusivos a estas figuras, es "Buster Keaton busca por el bosque a su novia, que es una verdadera vaca", un "poema representable". En este poema, describe Casado, Alberti muestra un lado patético, una "torpeza exaltada" del famoso cómico ${ }^{47}$. Además, una de las estrofas muestra cómo él encuentra un carácter existencial de Keaton, a través de una metáfora que se halla también en un análisis que María Zambrano hace sobre Chaplin, en la cual se vincula al hombre trajeado en medio de la lluvia, de la intemperie, como una especie de sinécdoque del vacío existencial. Así lo escribió Alberti:

Hasta los grillos se apiadan de mí

y me acompaña en mi dolor la garrapata

Compadécete del smoking que te busca y te llora

entre los aguaceros

y el sombrero hongo que tiernamente

te presiente de mata en mata. ${ }^{48}$

Federico García Lorca también escribió sobre esta figura fílmica. Lo hizo en 1928, en un texto teatral breve titulado "El paseo de Buster Keaton", donde utiliza a Keaton como símbolo de la homosexualidad ${ }^{49}$. En una de las didascalias presta atención a la mirada de Buster K. Describe sus ojos de esta manera:

[...] Sus ojos infinitos y tristes como los de una bestia recién nacida, sueñan lirios, ángeles y cinturones de seda. Sus ojos que son de culo de vaso. Sus ojos de niño tonto. Que son feísimos. Que son bellísimos. Sus ojos de avestruz. Sus ojos humanos en el equilibrio seguro de la melancolía.

En obras como Así que pasen cinco años y El público, de García Lorca, aparecen arlequines y un payaso, figuras que serán recurrentes, también, en sus dibujos y cuyo referente directo serán las obras de Picasso y Rouault, de acuerdo con José Luis Plaza Chillón. Especialmente, el académico pone atención a "Payaso de rostro desdoblado y cáliz", de 1927, porque tiene una "alusión cristológica [que] se evidencia en uno de los rostros desdoblados que llora sus lágrimas de color rojo" 50 .

\footnotetext{
46 Ibid.

47 Ibid.

48 Alberti, R., 100 poemas, Madrid, De la Torre, 2006, p. 59.

49 Casado, M., La nostalgia inseparable de Rafael Alberti. Oscuridad y exilio intimo en su obra, op. cit., p. 101.

${ }^{50}$ Plaza Chillón, J.L., "Payasos, pierrots y saltimbanquis: su dimensión autobiográfica y social en Picasso y Federico García Lorca”, op. cit., p. 99.
} 
Esta relación entre la imagen cristiana y el clown también está presente en el pensamiento de Zambrano, quien vincula la figura con el cordero sacrificado. Plaza Chillón sostiene que Rouault fue uno de los primeros que relacionó al clown con el sufrimiento de Cristo, así como la puesta en escena de la condición humana: "Impregna [Rouault] a sus personajes una inmensa tristeza y una profunda piedad, describiendo la dialéctica entre la existencia y la apariencia, además de la condición humana en el escenario del mundo" 51.

En el caso de Picasso, este pintor toma al arlequín, al saltimbanqui, al funámbulo y al payaso como parte de su repertorio pictórico. Los muestra "desprovistos de teatralidad, de toda alegría de circo, antes al contrario, subrayando aún demasiado el patetismo humano del profesional de la diversión que se alimenta mal" ${ }^{52}$. Pertenecen a la denominada época rosa de Picasso, que surge a partir de 1906, aproximadamente. Respondía

[...] a las propensiones psicológicas del hombre contemporáneo [...] Al mundo le costó mucho trabajo - le cuesta todavía- aceptar aquel trastorno de toda la tradición artística. Los cubistas y picasso más que ninguno, fueron por mucho tiempo piedra de escándalo. Se habló de clownismo, de esnobismo, de conspiración mercantil para sorpresa de incautos adinerados (...) la nueva concepción artística, lejos de denunciar su falsedad con una rápida desaparición, se afirmaba cada vez más en el gusto de las gentes, extendiéndose al arte literario, donde sus principios operaron una transformación decisiva, e influyendo en general, desde la arquitectura hasta la decoración, sobre todas las zonas de belleza ${ }^{53}$.

Otro de los artistas de la Generación del 27 que se dejó influenciar por este clownismo es León Felipe. Ernesto Cardenal cuenta que en alguna ocasión el poeta escribió un poema llamado "El payaso", que le dedicó. "En el poema dice que ha tenido que llegar a la vejez para averiguar que el poeta es un payaso, y que da saltos mortales hasta que una vez da el gran salto mortal y cae en el regazo de Dios" ${ }^{4}$. En otro texto, "El payaso de las bofetadas" (Habana y México, 1938), León Felipe escribe que Don Quijote "no es más que un clown. El gran payaso ibérico de las bofetadas. También la pirueta grotesca y finámbúlica es española. Don Quijote es el clown por antonomasia" 55 . Asimismo, que "los redentores del mundo han sido locos y derrotado"s", quienes antes de convertirse en dioses fueron payasos, una figura con la que relaciona a Cristo, quien

\footnotetext{
${ }^{51}$ Ibid., p. 98.

52 Mañach, J., “El arte de Pablo Picasso”, en Revista Hispánica Moderna, Año III, No. 3 (1937), p. 36.

53 Ibid., p. 37.

${ }^{54}$ Cardenal, E., Las insulas extrañas. Memorias II, México, Fondo de Cultura Económica, 2013 (versión digital).

55 Felipe, L., Nueva antología rota León Felipe, Madrid, AKAL, 2008, p. 44.

56 Ibid., p. 43
} 
[...] fue un payaso. Los que le abofetearon siempre... Los grandes empresarios eclesiásticos que han vivido de la divina resistencia de Jesús para las bofetadas ahora quieren hacerle Rey... Rey de verdad, con cetro de oro, duro y de verdad... Ya le han explotado bastante como clown, como Rey de Pantomima, con su cetro de cańa de escoba y su corona de sarmientos" 57 .

La farsa, escribe, nace "cuando el héroe se hace clown y la hazaña pantomima. Cuando aparece Don Quijote y entra España en la Historia ${ }^{58}$. Y continúa, preguntándose qué es la justicia:

[...] El clown, el hombre, tiene que preguntar una vez: Esta pantomima sangrienta y desgarrada, este truco monstruoso y despiadado que está aquí ahora en la picota del escarnio... ¿Para qué? ¿Qué significa? ¿Adónde vamos? ¿Adónde nos lleva todo esto? ¿A la justicia? Pero ¿qué es la justicia? ¿Existe la justicia? Si no existe, ¿para qué está aquí Don Quijote? Y si existe, ¿la justicia es esto? ¿Un truco de pista? ¿Un número de circo? ¿Un pim-pam-pum de feria? ¿Un vocablo gracioso para distraer a los hombres y a los dioses? Respondedme... Respondedme. Que me conteste alguien... ¿Qué es la justicia? Silencio... Silencio ${ }^{59}$.

Y cuando el clown-Don Quijote habla, interpreta León Felipe, es para decir "basta":

¡Que no se ría nadie! ¡Que no se ría nadie! Mi sangre de clown vale tanto como la sangre de los cristos. ¡Yo no soy un payaso! ¡Yo soy Prometeo! Vengo de la casta de los viejos redentores del mundo, y he dado mi sangre, no para hacer reír a los dioses y a los hombres sino para fecundar el yermo ${ }^{60}$.

\section{El payaso y la libertad}

María Zambrano ubica el arte del clown en el universo del folklore, la persistencia viviente de creencias y sentires en los que se expresa la "espontaneidad del alma de un pueblo" ${ }^{61}$, un arte humilde que, dice la filósofa, se pierde en la noche de los tiempos, pero que tiene una fragancia imperecedera que encanta y atrae inagota-

\footnotetext{
57 Ibid.

58 Ibid., p. 44.

59 Ibid., pp. 45-46.

${ }^{60}$ Ibid., p. 46.

${ }^{61}$ Zambrano, M. "El payaso y la filosofía, op. cit., p. 117.
} 
blemente. $\mathrm{Al}$ mismo tiempo, lo reconoce como un arte que muestra la historia de una tradición, la historia que no pasa, y esconde secretos de la condición humana ${ }^{62}$. Pero, para ella, el payaso es una figura constante, como las obras clásicas, como el Don Quijote o el Romancero. Una obra de arte que se convierte en "alimento para todos", porque "para todos juega el payaso la eterna pantomima" ${ }^{63}$.

Uno de los encuentros trascendentales de la filósofa con esta figura se dio, precisamente, en el espectáculo de Grock. Para Zambrano, en consonancia con las ideas de la "otra" generación del 27, este artista no iba tras la risa facilona de un chiste común, sino que provocaba en su público una sonrisa: "lo más delicado de la expresión humana, que florece de preferencia en la intimidad, y aun a solas; comentario silencioso de los discretos, arma de los tímidos y expresión de las verdades que, por $\tan$ hondas o entrañables, no pueden decirse" ${ }^{64}$. La sonrisa, escribe, nace de un "clima de meditación”, donde se reconocen verdades que resultan demasiado íntimas. Pero también hay una venganza sutil. "Y cuando es una multitud la que sonríe, será, debe de ser, porque se siente vengada en forma pacífica, armoniosa, de algo que soporta, que ha de soportar difícilmente" ${ }^{65}$. A la sonrisa, Zambrano le dedica varias líneas de su texto. Lo hace así porque ella misma se miró en Grock, se reconoció en él. Ella, la mujer que se debatía entre su poesía y su filosofía, de pronto descubrió, en ese ser extraño, al hombre que piensa, ese que al pensar se retira, como el que mira, para poder ver mejor. Pero ese que piensa no lleva una dirección lineal ni segura, sino que duda, vacila, es un camino de búsqueda que el payaso realiza todo el tiempo de manera plástica y poética, pero que sólo es visible cuando es permitido. "Y la hace visible también desde el otro, desde el hombre que ve pensar a otro sin acabar de darse cuenta de lo que está sucediendo ante sí; ve solamente a alguien que tropieza" ${ }^{66}$. Pero no es que la actitud del otro sea pasiva, sino que algo mira, algo reconoce y por eso sonríe.

Estas reflexiones las hizo después de varios años de vivir en un exilio que comenzó en 1939. Las registró en "El payaso y la filosofía”, este ensayo que apareció publicado en 1957, en la revista La palabra y el hombre, de la Universidad Veracruzana. El texto deja entrever influencias, en la pensadora, de algunos integrantes de la Generación del 27 y la huella que dejó en ella el espectáculo de Grock. María Zambrano dialoga con el arte del clown y con la sonrisa que provoca en quien lo

\footnotetext{
62 Ibid.

63 Ibid.

${ }^{64}$ Ibid., pp. 117-118.

65 Ibid., p. 118.

66 Ibid., p. 119.
} 
mira, una sonrisa a la que le da estatus de "símbolo de la verdad y de la libertad, del espíritu como se ha nombrado a veces, de lo que libra al hombre de ser nada más que un manojo de instintos. Un símbolo de ese poder que no se acaba" ${ }^{67}$. Ella encuentra en ese clown al que piensa y se mueve en otro espacio y en otro tiempo, como ella misma en su tránsito por el no-lugar. Mira en ese clown al hombre que es enteramente libre, el que piensa porque es libre. "Y el pensamiento mismo es la libertad" 68.

Es, quizá, "El payaso y la filosofía" un ejercicio de recuperación y de reivindicación de su generación. De reconocer su capacidad de libertad, sus deseos de ruptura con un status quo que les afecta. La presencia de Grock en los escenarios madrileńos de los tempranos años 30 pudo haber sido reclbido así, como el símbolo de esa libertad que da el asumirse como somos, con lo que no nos gusta, con lo que no queremos. El texto de Zambrano es un guińo lanzado a su pasado, a todos los que vieron en esta figura una libertad amable, una libertad que no es revolucionaria de manera violenta, que es discreta, que vacila, que se tambalea a ratos, pero que piensa, que conecta con el otro, que lo reconoce como otro, otro humano, y juntos construyen un nuevo espacio que permita libertad. ¿Es acaso ahí donde puede entenderse la lucha y la provocación que emprendieron algunos por hacer presente a esta figura en otros escenarios, como ocurrió con Alberti?

La revolución del payaso pasa desapercIbida. Para la multitud, dice Zambrano, este ser podría ser visto como un imbécil, pero no es sino un hombre que está pensando, porque el acto de pensar también puede llegar a ser objeto de burla, de sorna; incluso, critica la filósofa, de los amigos cercanos, quienes, "con la mejor de las intenciones [dicen] frases como estás, salidas de la impaciencia consuetudinaria: Pero no lo pienses ya más; vamos, haz algo. O el tradicional: No pienses, que eso no sirve para nada" "69. María Zambrano mira en el payaso al filósofo y, en las humillaciones que recibe y acepta por vocación, identifica también las vejaciones que padecen quienes dedican su tiempo y su vida a pensar. En ello, reconoce las propias. Es un ejercicio de autoconfesión. Son las palabras de alguien que ha sufrido, tal vez en silencio, por ser mujer, por ser escritora, por ser poeta y vivir al margen prácticamente en todas las facetas de su existencia. Zambrano, sin decirlo, habla de sus dudas, pero también las de toda su generación, que no es sino la de todo aquél que anhela la libertad, libertad que provoca miedo y sufrimiento: "Sufren cuando se ven privados de ella y la rechazan cuando la tienen. Diríase que lo más humano

\footnotetext{
${ }^{67}$ Ibid.

68 Ibid.

69 Ibid.
} 
es querer la libertad para no usarla en momentos de embriaguez, de pasión o de entusiasmo, cuando ya deja de ser verdaderamente libertad y linda con el delirio" ${ }^{70}$.

Es esta lucha por la libertad donde el clown provocó a la Generación del 27. A Zambrano y a todos estos intelectuales se les reveló en el tiempo de la preguerra, de los ideales por construir un porvernir liberador, en la búsqueda por hacer de España una otra nación. Dos décadas después, el escenario era distinto. Zambrano reflexiona sobre la experiencia en un tiempo afectado, el de la derrota. En donde la patria se convirtió en el sin-mundo para ella. Ahí, en ese tiempo-espacio otros, se ve a sí misma en la imagen que le devuelve el espejo del recuerdo de aquella función que con tanto entusiasmo promocionó Gómez de la Serna en el 32. Un espejo que le muestra su propio conflicto, el del exilio, el de la libertad que podría darle el no-lugar, pero que la deja en la vacilación de la no-acción, que se le revela en una risa, como la que notó en el viejo Grock. Así lo dice: "Y cuando el payaso mimetiza ese conflicto, aun en la forma más burda, se siente liberado por un instante y ríe, ríe sin saber por qué. Pues casi siempre reímos sin saber de qué. Si supiéramos descifrar lo que se esconde en la risa" ${ }^{71}$.

Hay, sin embargo, una diferencia que Zambrano encuentra entre el clown y el filósofo. El primero "es un muerto que finge estar vivo". Y como está muerto, todo lo sabe y ya nada le importa. Y al no importarle, encuentra aquello que lo hace profundamente humano: la caridad. El filósofo, en cambio, se encuentra todavía vivo, dice la filósofa y con ello provoca preguntas: ¿en dónde se encuentra ella cuando escribe este texto? ¿En el mundo de los vivos o en el de los muertos? ¿Cuál es la experiencia existencial que le han dejado esos primeros años en el exilio? Vive sus años fuera de España como derrotada y el clown es la figura del que está acabado para una sociedad normalizada (¿̇anestesiada, quizá?), pero no lo está desde la lógica de la comunión, de la caridad, del humano, del que se atreve a mirar al otro desde su intemperie, desde una libertad que se afirma en este acto compasional y en la sonrisa, desde la libertad de seguir pensando sin que se note y, con ello, cargar "con el peso de la propia existencia" y, al hacerlo, ser "de verdad, libre" ${ }^{72}$.

\footnotetext{
${ }^{70}$ Ibid.

${ }^{71}$ Ibid.

72 Ibid., p. 120.
} 


\section{Referencias Bibliográficas}

Alberti, R., 100 poemas, Madrid, De la Torre, 2006.

Balló, T., Las sinsombrero. Sin ellas, la historia no está completa. Madrid, Planeta, 2016 (versión electrónica).

Berenguer Vigo, A., María Zambrano y la raíz desnuda, Libros.com, 2016 (versión electrónica)

Brinuega, J., 2015, "El fulgor de un epílogo. Dos obras de la última etapa de Alberto". Museo de Bellas Artes de Bilbao, p. 6. (versión electrónica).

Cardenal, E., Las insulas extrañas. Memorias II, México, Fondo de Cultura Económica, 2013 (versión digital).

Casado, M., La nostalgia inseparable de Rafael Alberti. Oscuridad y exilio intimo en su obra, Madrid, De la Torre, 2017.

Díaz Pardo, F., Breve historia de la Generación del 27. Vanguardias españolas, Madrid, Nowtilus, 2018.

EL PAís, "Rafael Barradas", en El País, Madrid (2013), (versión electrónica).

Felipe, L., Nueva antología rota León Felipe, Madrid, AKAL, 2008.

Fortuño Llorens, S., Vanguardia y humorismo. La otra generación del 27, Valencia, Universitat Jaume I, 1998.

Gómez De La Serna, R., "El clown Grock", en Luz, 13 octubre de 1932.

Gómez De La Serna, R., Ismos, Madrid, Guadarrama, 1975.

Huárag Álvarez, E., Generación del 27. Virtuosismo metafórico y hondura existencial, Lima, Pontificia Universidad Católica del Perú, 2004.

Mañach, J., "El arte de Pablo Picasso", en Revista Hispánica Moderna, Año III, No. 3 (1937).

Navas Ocaña, I., "Las escritoras del 27 y los cometas", en Romance Notes, University of North Carolina at Chaple Hill, Vol. 50, No. 2 (2010). https://doi. org/10.1353/rmc.2010.0030

Ortega, J., Chaplin. La sonrisa del vagabundo. Berenice, 2008 (versión electrónica).

Peral Vega, E. Pierrot/Lorca. White Carnival of Black Desire, Tamesis: Boydell \& Brewer, 2015. 
Plaza Chillón, J.L., "Payasos, pierrots y saltimbanquis: su dimensión autobiográfica y social en Picasso y Federico García Lorca", en Cuadernos de Arte Granada, 43 (2012).

Ripoll, J.R., "Primera lectura de Marinero en tierra”, en Martínez Torrón, D., Juan Ramón, Alberti. Dos poetas líricos, Kassel, Reichenberger, 2006.

Zambrano, M., "El payaso y la filosofía, en Aurora (2012).

DOI: https://doi.org/10.15366/bp2020.25.010

Bajo Palabra. II Época. No25. Pgs: 221-238 